\title{
On the Design of Affordable and Green High-Performance Routers for Community Networks
}

\author{
Amos Nungu \\ $\mathrm{KTH}$ \\ Telecommunication Systems Lab \\ Forum 120, 16440 Kista, Sweden \\ +46737724872 \\ amnungu@kth.se
}

\author{
Robert Olsson \\ $\mathrm{KTH}$ \\ Telecommunication Systems Lab \\ Forum 120, 16440 Kista, Sweden \\ +46704250676 \\ robert@herjulf.net
}

\author{
Björn Pehrson \\ $\mathrm{KTH}$ \\ Telecommunication Systems Lab \\ Forum 120, 16440 Kista, Sweden \\ +46706256140 \\ bpehrson@kth.se
}

\begin{abstract}
We argue that large scale user-driven community networks are becoming viable in areas without access to telecommunication services due to lack of commercial interest. We discuss the design of a key component supporting this claim: a high-performance, low-power-consuming and affordable router with fibre optic capable of forwarding $2 \mathrm{Gbps}, 220 \mathrm{kpps}$, powered by only $25 \mathrm{~W}$, which is between $7 \%$ and $17 \%$ of the alternatives in our comparison. The cost of the one-off prototype was below a third of the prices of comparable proprietary solutions and half of other open source alternatives. It can be reduced further in series production. Future work will include widening of bottlenecks without increasing cost and field tests in rural African settings.
\end{abstract}

\section{Categories and Subject Descriptors \\ D.2.6[Computer Communication Networks]: Internetwork Routers}

\section{General Terms \\ Design, Experimentation, Measurement, Performance.}

\section{Keywords}

Router architecture, Open Source routing, Robust low-cost design, Developing Regions.

\section{INTRODUCTION}

Access to communication networks and services, broadband and mobile, is a prerequisite to keep up with your peers, whether you are a country, an organization or an individual.

There is the misconception that such access is provided by commercial markets, if there is only a demand. This may be true in densely populated areas of developed regions. It is, however, definitely not true in developing regions nor in sparsely populated areas of developed regions, and the definition of what is sparse varies considerably. Even in developed regions, like Europe, about

Permission to make digital or hard copies of all or part of this work for personal or classroom use is granted without fee provided that copies are not made or distributed for profit or commercial advantage and that copies bear this notice and the full citation on the first page. To copy otherwise, or republish, to post on servers or to redistribute to lists, requires prior specific permission and/or a fee. NSDR'10, June 15, 2010, San Francisco, CA, USA.

Copyright 2010 ACM 978-1-4503-0193-0/10/06 ..\$10.00.
$10 \%$ of the households live in areas without such access and operators require contributions from universal access funds to go there due to the requirements of their business models. In developing regions, including most of Africa, the number is closer to $90 \%$, at least on the broadband side.

Currently, communication network services in the developing world are far less advanced than in the developed counterparts. There are many reasons behind this, including under-developed policies and regulatory frameworks creating political risks, lack of all sorts of infrastructures, such as copper and optical fibre wirelines, electrical power and developed supply chains, as well as poor commercial viability of traditional business models for network operators and service provider leading to high perceived commercial risks, etc.

Another reason is that the network equipment manufacturers are also controlled by the business models of their customers, the operators, and thus focused on the development of complex and expensive proprietary technical solutions for extreme traffic volumes and quality of service requirements.

Equally problematic is the fact that most of the core network equipment is power-hungry and dependent on electricity supplied from the power grid, which is often unstable. Little attempt has been made to utilize alternative sources of energy in ICT applications, which could provide sustainable, stable and reliable power supply for infrastructure network equipment.

To address these challenges, there is a need to organise a userdriven community networking action to develop technical solutions as well as guidelines for how to deploy, manage and maintain sustainable high-performance community networks in under-served areas. We advocate the use of open source software, selected standard hardware and renewable energy solutions. By levering the performance increases of standard hardware and the power of open source communities, open networking systems can provide solutions that achieve superior performance at a fraction of the cost of comparable proprietary systems.

\section{RELATED WORK}

To the best our knowledge, a complete hardware design of a highperformance open source software-based router, including analysis of routing performance, power consumption of individual components with the objective to minimize the total system power consumption and cost has not been reported before. In [1], the general relation between performance and power consumption is studied while in [2] and [4], the architectural bottlenecks limiting 
performance are explored. In [6], the use of open source software routers in $10 \mathrm{Gbps}$ production networks is reported.

\section{IMPLEMENTATION}

The goal of our work is to build low cost, low power, high performance routers to be used in community networks. Such networks are emerging in many rural areas where purchasing power is very low and power supply is problematic.

We have designed and implemented a reliable, high performance, low-cost, low-power, completely fan-less router that uses an average power of 25 watts, supports fibre and copper links at Gbps speeds with a throughput of 2 Gbps or $220 \mathrm{Kpps}$. The router is housed inside a lightweight, rack mounted aluminium chassis. Linux/Bifrost [5] was the software distribution of choice.

Components used to build our router are summarized in table 1 together with the cost in percent of total cost of the one-off prototype, which was 1,110 USD.

Table 1: Hardware equipment cost - (2009)

\begin{tabular}{|l|l|c|}
\hline$\#$ & Item & \% \\
\hline 1 & NIC:InterfaceMasters Niagara4NE-76-4 with DOM & 38 \\
\hline 2 & Travla C-159 rackmount chassis & 22 \\
\hline 3 & Motherboard/CPU (Quanmax KEEX-2030) & 19 \\
\hline 4 & PCI-e extension cable PE-FLEX4-15” & 6 \\
\hline 5 & PCI-e right-angled extension cable PE-FLEX4-12' & 6 \\
\hline 6 & Copper SFP module & 4 \\
\hline 7 & Main Memory (Kingston 1 GB SODIMM RAM) & 2 \\
\hline 8 & AC/DC configurable power adapter & 2 \\
\hline 9 & Storage (SanDisk Cruzer USB 2.0 2GB & 1 \\
\hline & TOTAL COST in USD & 1,110 \\
\hline
\end{tabular}

\section{PERFORMANCE EVALUATION}

Routing performance is summarized in table 2 while power consumption of individual components is summarized in table 3 .

Table 2. Routing performance and power consumption

\begin{tabular}{|l|l|}
\hline Characteristic & $\underline{\text { Amount }}$ \\
\hline Routing throughput (packet rate) & $220 \mathrm{Kpps}$ \\
\hline Routing throughput (data rate) & $2 \mathrm{Gbps}$ \\
\hline $\begin{array}{l}\text { Power Consumption when idle } \\
\begin{array}{l}\text { Power Consumption when routing in } \\
\text { maximum packet rate (2 copper interfaces) }\end{array}\end{array}$ & $21.7 \mathrm{~W}$ \\
\hline
\end{tabular}

Table 3. Power consumption of various components

\begin{tabular}{|l|l|}
\hline Component & Power \\
\hline Motherboard (idle) & $8.4 \mathrm{~W}$ \\
\hline 4-SFP port NIC with no SFP module installed (idle) & $7.5 \mathrm{~W}$ \\
\hline Copper SFP module (no link and idle) & $0.2 \mathrm{~W}$ \\
\hline Copper SFP module (link up and idle) & $1.5 \mathrm{~W}$ \\
\hline Onboard Gigabit Ethernet interface (link up and idle) & $0.5 \mathrm{~W}$ \\
\hline
\end{tabular}

\section{FUTURE WORK}

Future work include further performance and energy consumption tests in different scenarios. Also, we need to devise a general principal in component selection that will yield a reasonable high performance, low power consumption ratio. We plan to deploy the router into our production network in Serengeti [3] Tanzania, to carry further tests in a live network.

\section{ACKNOWLEDGMENTS}

The contribution of the MinNE student team making the actual implementation and testing of the prototype [7] in the Communication Systems Design framework (CSD) [8] is gratefully acknowledged.

\section{REFERENCES}

[1] Bolla R., Bruschi R., Ranieri A. Performance and Power Consumption Modeling for Green COTS Software Router. COMSNETS 2009

[2] Bianco A., Finochietto J.M., Galante G., Mellia M. and Neri F. Open-SourcePC-Based Software Routers: A viable Approach to High-Performance Packet Switching. LNCS 3375,pp.353-366,Springer-VerlagBerlinHeidelberg2005

[3] Nungu A., Genesis N., Pehrson B. Serengeti Broadband. The 2nd ACM SIGCOMM Workshop on Networked Systems for Developing Regions (NSDR 2008), Seattle, August 2008.

[4] Bolla R., Bruschi R., PC-based Software Routers: High Performance and Application Service Support. ACM PRESTO 2008.

[5] Bifrost Network Project, http://bifrost.slu.se/.

[6] Hagsand O. et al. "Towards 10Gbps open source routing", Linux kongress 2008. Hamburg Oct 2008.

[7] Minimal Network Element (MinNE) student project website: www.tslab.ssvl.kth.se/csd/projects/0921191/

[8] Communication Systems Design, a problem oriented projectdriven environment integrating development and learning: www.tslab.ssvl.kth.se/csd/ 